\title{
A Study on Effectiveness of Stress Management Programme among Physical Education Teachers
}

\author{
Dr Abhishek Chowdhery ${ }^{1 *}$, Dr Jaydeep Nandi ${ }^{2}$
}

\section{ABSTRACT}

Aim: The purpose of this study was to find out the effectiveness of stress management programme among Physical education teachers. Objectives: To identify the level of stress and to test the effect of stress management among Physical education teachers. Methods: One hundred and twenty one participants were involved in the study to prove the effectiveness of stress management techniques among the Physical education teachers by using stress questionnaire. The purpose of the study was to determine the effectiveness of stress management program among Teachers. Before starting the techniques were introduced and the stress questionnaire was used for pre-test. The program starts from coping skill to verbalization the same stress questionnaire is given for the post test purpose. Results: The results showed that there was a significant difference between the pre and post test of stress questionnaire (75.386 if $\mathrm{p}=0.000$ ). The stress level was said to be reduced after the application of stress management techniques. Conclusion: Study concluded that various relaxation techniques should be established for reducing the level of stress on the Physical education Teachers.

Keywords: Stress, Relaxation Technique.

The term stress generally refers to the reactions of the body to certain events or stimuli that the organism perceives as potentially harmful or distressful. Such stress inducing events or stimuli, which are referred to stressors, can be either physical or psychological in nature ${ }^{1}$. The degree to which perceived controllability alters the way stressor is experience varies greatly among individuals ${ }^{2}$. Occupational Stress is a term used to define ongoing stress that is related to the work place. The stress may have to do with responsibilities associated with the work itself, or be caused by condition that are based in the corporate culture or personality conflicts. As with other

\footnotetext{
${ }^{1}$ Assistant Professor, Department of Physical Medicine and rehabilitation - V.C.S.G. Govt. Medical College and research Institute, Srinagar Pauri Garhwal, Uttarakhand, India

${ }^{2}$ Senior resident, Department of Physical Medicine and rehabilitation - V.C.S.G. Govt. Medical College and research Institute, Srinagar Pauri Garhwal, Uttarakhand, India

*Responding Author

(C) 2016 I A Chowdhery, J Nandi; licensee IJIP. This is an Open Access Research distributed under the terms of the Creative Commons Attribution License (http://creativecommons.org/licenses/by/2.0), which permits unrestricted use, distribution, and reproduction in any Medium, provided the original work is properly cited.
} 


\section{A Study on Effectiveness of Stress Management Programme among Physical Education Teachers}

forms of tension, occupational stress can eventually affect both physical and emotional well being if not managed effectively ${ }^{3}$.

Former teacher and educational researcher Dr Kevin Eames says the pressures of the job are very intense and draining. The helpline has thousands of calls and e-mails every year from teachers struggling to protect their wellbeing at work. Objectively, teaching has got to be one of the top 5 most stressful careers in the world. In a single hour, we can play many different roles: counselor, administrator, parental doormat, paper pusher, and maybe, if we're lucky, educator.

The effectiveness of brief group training in meditation or Progressive Muscular Relaxation reduces state anxiety after exposure to a transitory stressor ${ }^{4}$. Psychological stress may led to increased rates of anxiety and depression. Aerobic exercise is frequently described as having positive effects on psychological well-being by enhancing mood and reducing anxiety ${ }^{5}$. The schizophrenic patient's improved on 7 to 20 items of the state-Trait Anxiety Inventory demonstrated the effectiveness of even a short-term stress management program ${ }^{6}$.

\section{METHODOLOGY}

\section{Research Design}

Quantitative and Experimental study

\section{Samples}

This study was conducted on 121 Physical education Teachers with the age group of 30-65 years from teacher association of Ballia - Uttar Pradesh.

\section{Screening Criteria}

$>$ Teachers.

$>\quad$ Age Group of $30-65$ years, minimum 5 year experience

\section{Questionnaire Used}

The questionnaire developed by Latha ${ }^{7}$ consists of 52 items arranged from mild stress, moderate to severe stress this lists the life experiences based on the amount of change or adjustment one has to make to life rather than the undesirability of events themselves.

Stress questionnaire - Test retest reliability of 0.87 ,

Good concurrent validity

Score interpretation

$0-17$ low stress

18 - 35 moderate stress

36 - 52 high stress

\section{Data Collection Procedures}

The study was explained to the secretary of the teachers association. Association consent form was obtained from the President and secretary of the Ballia district (U.P) Adarsh teacher 


\section{A Study on Effectiveness of Stress Management Programme among Physical Education Teachers}

association. Pre-test was done by using the stress questionnaires. After the intervention post test was done by using the stress questionnaires.

Intervention starts with the progressive muscular relaxation techniques (Jacobson) to the verbalization for the patients. It includes coping skills strategies, aerobic exercises, autogenic training, communication skills, deep breathing laughter, meditation, time management and verbalization.

\section{Jacobson Techniques:}

Jacobson was a renowned behavior therapist who evolved this procedure. By clinching and relaxing various part of the body.

\section{Aerobic Exercises:}

Early morning it is done for 20 - 30 minutes. It involves repetitive, rhythmic contractions of the large muscles of the legs and arms. Aerobic exercise appears to be an effective mood regulating behavior $^{8}$.

\section{Autogenic Training:}

It uses self-hypnosis and mental imagery to achieve relaxation. It typically involves imagining sensations of physical heaviness and warmth to achieve muscle relaxation and vasodilatation.

Imaging oneself in settings where one would feel warm, comfortable, and heavy can facilitate these Suggestions

Autogenic training is an effective adjunctive treatment for stress-related conditions ${ }^{9}$.

Autogenic training is an effective adjunctive treatment for stress-related conditions ${ }^{9}$. It is not recommended for people who are agitated or actively psychotic ${ }^{10}$.

\section{Communication Skills:}

Clarifying expectations, defining needs honestly and providing tactful and structured feedback, can decrease the number of stressful understandings.

Social skills training and assertive training programs are an important part of stress management for certain client populations ${ }^{11}$.

\section{Deep Breathing:}

Deep breathing involves slowly inhaling and exhaling to reduce tension in the shoulders, trunk and abdomen. The process begins with focusing on normal breathing in a quiet and comfortable place. This is followed by a period of deep inhalation and slow exhalation. (During inhalation, the abdominal muscles should be relaxed. During exhalation, abdominal muscles should be contracted. It is often helpful to rest a hand lightly on the abdomen during this process. 


\section{A Study on Effectiveness of Stress Management Programme among Physical Education Teachers}

Deep abdominal breathing has been demonstrated to reduce physiological responsiveness ${ }^{12}$, 15 minutes with $2-3$ minutes interval.

\section{Laughter:}

Laughter's may stimulate the release of endorphins, the brain's endogenous opiates, hereby helping to alleviate pain and stress ${ }^{13}$.

\section{Meditation:}

Meditation involves focusing attention on a rhythmic, repetitive word, phrase or sensation (e.g. breathing, heart rate) to achieve relaxation. Mental process blocks the stress response of the sympathetic nervous system by activating the anterior hypothalamus which controls the parasympathetic nervous system ${ }^{14}$. Each technique has to be taught to the patient for more than twenty minutes up to forty five minutes for twenty patients at a time in one set up per day. This has to continue minimum eight to twelve weeks sessions at various rehabilitation centers.

\section{Data Analysis Procedure}

Data analysis carried out uses SPSS (version 10.0).

\section{RESULTS AND INTERPRETATION}

In this study one hundred and twenty one subjects between the age group of 30 to 65 were selected. All are selected from the Teacher Association of Ballia-U.P

Table 1.1 - The Demographic Distribution Of Variable

\begin{tabular}{|l|l|}
\hline Gender & Sample size \\
\hline Male & 121 \\
\hline
\end{tabular}

Table 1.2- Pre And Post Test Values Of All Range

\begin{tabular}{|l|l|l|l|l|l|}
\hline S.No. & Scoring Range & $\begin{array}{l}\text { Pre-Test No. of } \\
\text { Patients }\end{array}$ & $\begin{array}{l}\text { Post-Test No. of } \\
\text { patients }\end{array}$ & $\begin{array}{l}\text { Chi-square } \\
\text { Value }\end{array}$ & $\begin{array}{l}\text { P } \\
\text { Value }\end{array}$ \\
\hline 1. & Range 0-17 & 26 & 92 & \\
\cline { 1 - 3 } 2. & Range 18-35 & 93 & 29 & \multirow{2}{*}{75.386} & \\
\cline { 1 - 3 } 3. & Range 36-52 & 2 & 0 & & \\
\hline
\end{tabular}

$(\mathrm{p}=0.000)$

Chi-Square test was used to find whether, a significant difference was seen between the pre and post test. The results showed that there was a significant difference (75.386 if p value is 0.000 ) between the both tests. 


\section{A Study on Effectiveness of Stress Management Programme among Physical Education Teachers}

\section{DISCUSSION}

Stress is a part of our day to day life. The programs include coping skills training, aerobic exercises, autogenic training, communication skills, laughter, meditation, deep breathing, progressive muscular exercises, time management, and verbalization. The purpose of the study was to determine the effectiveness of stress management program among Physical education Teachers.

\section{CONCLUSION}

This study has been done to determine the effectiveness of stress management program for Physical education Teachers. The results concluded that stress has an influence on Physical education Teachers events and various relaxation techniques should be established for reducing the level of stress on Physical education Teacher.

\section{REFRENCES}

1. Kathleen. Brady and C sone - Parm D (1999) - Alcohol research and health vol-23-no-41999 -56-61 pg.

2. Timmy. Salomon's (2007) - Effect of perceived controllability of pain - journal of cognitive neuroscience 19(6)-993-2003.

3. Malcolm Tatum (2010)- Occupational stress - Weise geek publication nov-23:2011- 4549.

4. Rausch et.al (2006) - Neurocirculatry model of PTSD and extinction BIOI Psychiatry 2006 aug-15-60(4)-376-82.

5. Johansson, mattes, peter, John (2008) - International journal of stress management- vol 45-79-81.

6. Franklin stein (1989) - Teaching stress management technique to schizophrenic patient American journal of occupational therapy- march 1989-vol43- 162-169.

7. Latha (1988) - stress questionnaire developed by Dr Latha Sathish.

8. R.Thayer, Robert Newman, mc clain (1994)- Self regulation of mood - American Journal of Psychological association - vol 67 , no.5- 910-925.

9. Etler et al- (1995) - Treatment atopic dermatitis - A comparative study of psychological and dermatological approach to relapse preservation - Psychol- vol 44- 624-635.

10. Escobedo , Courtney (1990)- American journal of occupational Therapy - Stress Management Program - Inpatient to outpatient continuity -vol-44- 306-310.

11. Willard and spackman occupational therapy $9^{\text {th }}$ Edition - Lippincott - page 458-463.

12. Forbes EJ- (1993)- Psycho physiological effect of several stress management technique Feb 72 (1)-pg-19-27.

13. Cousin (1979) - Brain active role in healing for maintaining optimal health.

14. Benon (1975) - The relaxation technique response - Psycho physiological aspect and clinical application - Psychiatry Med- (6)- pg 87-98.

How to cite this article: A Chowdhery, J Nandi (2016), A Study on Effectiveness of Stress Management Programme among Physical Education Teachers, International Journal of Indian Psychology, Volume 3, Issue 3, No. 10, DIP: 18.01.177/20160303, ISBN: 978-1-365-19879-3 